Annales Geophysicae (2002) 20: 585-598 (c) European Geophysical Society 2002

\title{
Aeronomy, a 20th Century emergent science: the role of solar Lyman series
}

\author{
G. Kockarts \\ Institut d'Aéronomie spatiale de Belgique, 3 avenue Circulaire, B-1180 Brussels, Belgium
}

Received: 31 October 2001 - Revised: 23 January 2002 - Accepted: 29 January 2002

\begin{abstract}
Aeronomy is, by definition, a multidisciplinary science which can be used to study the terrestrial atmosphere, as well as any planetary atmosphere and even the interplanetary space. It was officially recognized in 1954 by the International Union of Geodesy and Geophysics. The major objective of the present paper is to show how aeronomy developed since its infancy. The subject is so large that a guideline has been chosen to see how aeronomy affects our atmospheric knowledge. This guideline is the solar Lyman alpha radiation which has different effects in the solar system. After a short description of the origins of aeronomy the first observations of this line are summarized since the beginning of the space age. Then the consequences of these observations are analyzed for the physics and chemistry of the neutral terrestrial atmosphere. New chemical processes had to be introduced, as well as new transport phenomena. Solar Lyman alpha also influences the structure of the Earth's ionosphere, particularly the D-region. In the terrestrial exosphere, solar Lyman alpha scattered resonantly by atomic hydrogen is at present the only way to estimate this constituent in an almost collisionless medium. Since planetary atmospheres also contain atomic hydrogen, the Lyman alpha line has been used to deduce the abundance of this constituent. The same is true for the interplanetary space where Lyman alpha observations can be a good tool to determine the concentration. The last section of the paper presents a question which is intended to stimulate further research in aeronomy.
\end{abstract}

Key words. Atmospheric composition and structure (middle atmosphere - composition and chemistry; thermosphere - composition and chemistry) - history of geophysics (atmospheric sciences)

\section{Origins}

The word "Aeronomy" has been coined by the great geophysicist Sidney Chapman. It can be defined as the science

Correspondence to: G. Kockarts (gaston.kockarts@oma.be) dealing with atmospheric regions where photodissociation and ionization processes play a role.

It was officially introduced during the 1954 General Assembly of the International Union of Geodesy and Geophysics (IUGG) in Rome. During this assembly the International Association of Magnetism and Electricity changed its name to become the International Association of Geomagnetism and Aeronomy. This official recognition of the term does not imply that no researchers were involved in aeronomy before that time. There have always been precursors in any science before the adoption of a specific name. During the ancient times, a human being observing the sky and trying to understand what he or she noticed was perhaps doing astronomy, meteorology or even aeronomy without knowing that she or he was a pioneer in one of these sciences now recognized by the scientific community.

At the beginning of the 20th Century, several authors made computations for the atmospheric composition (Hann, 1903; Humphreys, 1910; Wegener, 1911; Chapman and Milne, 1920; Jeans, 1925), including nitrogen, oxygen, argon, carbon dioxide, hydrogen, neon and helium. As noted by Jeans (1925), all these calculations assume that the terrestrial atmosphere is composed of two layers, one with an adiabatic regime up to approximately $11 \mathrm{~km}$ at mid-latitude and one with a constant temperature above that height. This was a consequence of observations available at that time. Wegener (1911) even introduced a hypothetical monoatomic constituent, called geo-coronium with a mass of $0.4 \mathrm{amu}$, in order to explain an unknown line in the auroral spectrum. This hypothesis was refuted by Chapman and Milne (1920), since the existence of such super light constituent would imply an escape flux so high that the constituent should disappear from the atmosphere. A historical, vertical distribution of the atmospheric composition is given in a table by Chapman and Milne (1920).

Figure 1 shows a graphical representation of these computations. It is clearly seen that the atmosphere is divided in two regions. Up to $20 \mathrm{~km}$ constituents are in perfect mixing and above that height molecular diffusion leads to a separation 


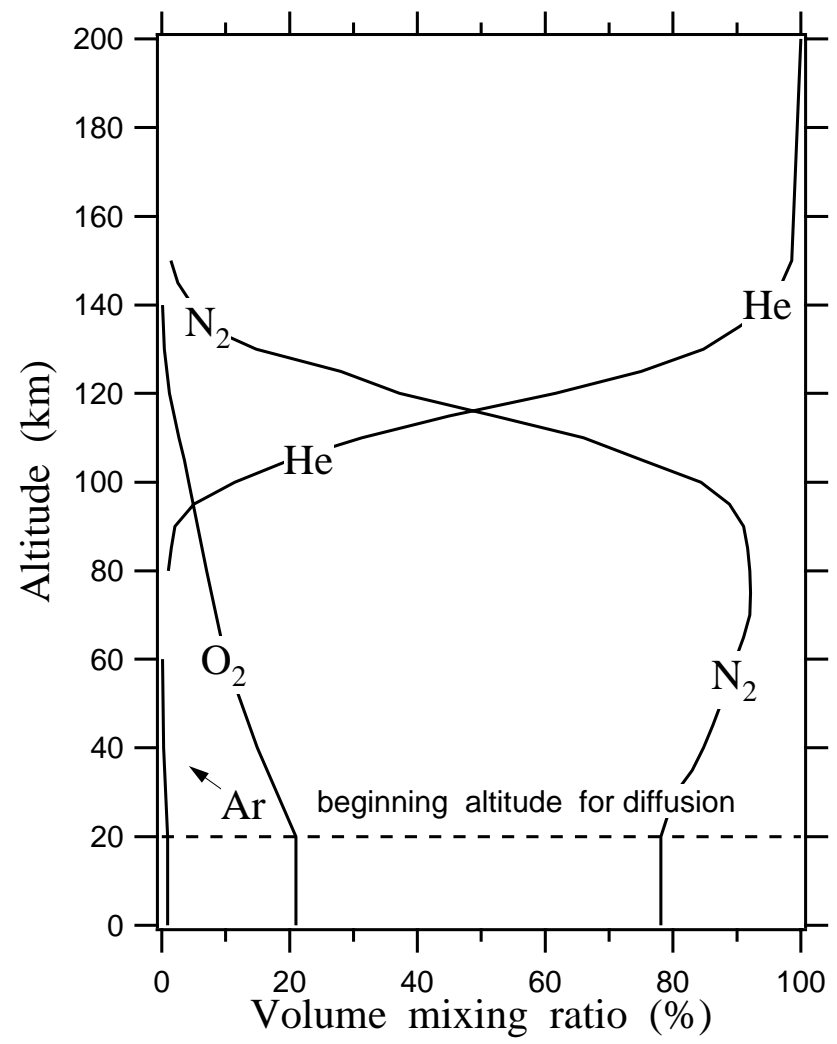

Fig. 1. Vertical distribution of volume mixing ratios computed by Chapman and Milne (1920).

of the atmospheric constituents according to their molecular mass. Although the altitude where diffusion begins is not correct, this figure demonstrates the concept of the different dynamical regimes between two regions now called the homosphere (perfect mixing) and the heterosphere (diffusive equilibrium). This example shows that Chapman and Milne (1920) already did excellent aeronomical work before the name "Aeronomy" was coined by Sidney Chapman.

In the present paper, I take the solar Lyman series as a guideline to show the multidisciplinary aspects of aeronomy, since a complete overview of this science would require several books. A reminder of the Lyman series is given in Sect. 2 and the first observations, as well as recent refinements, are described in Sect. 3. Then some implications for the neutral atmosphere are discussed in Sect. 4, and Sect. 5 indicates that the Lyman series also plays a significant role in the ionized part of our atmosphere. Knowledge of the outermost part of the atmosphere, i.e. the exosphere benefits from observations of the Lyman series, is shown in Sect. 6. Aeronomy is not limited to the terrestrial atmosphere, and it can lead to information for other planets and for the whole solar system. Aeronomy is still a science where important progress is ongoing. Therefore, a short sketch of its future is given in the last section. Younger scientists should not believe that everything has been done. There is plenty of work for the future and I am convinced that with imagination and skill, many surprises will arise in the $21^{\text {th }}$ Century.

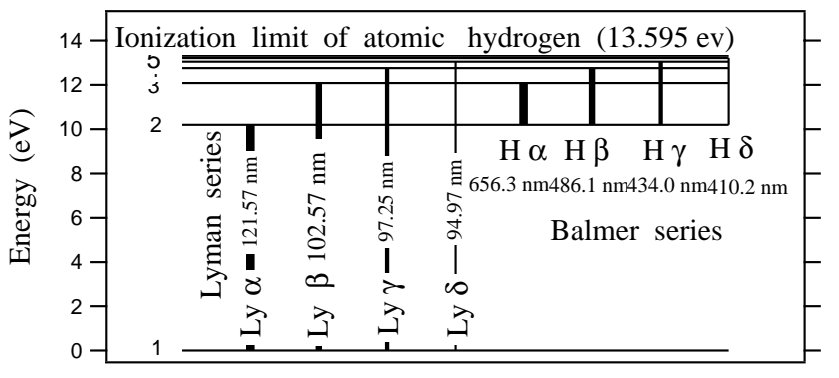

Fig. 2. Energy level diagram for atomic hydrogen.

Although the reference list at the end of the present paper is far from being exhaustive, I should mention that several books contain the word aeronomy in their title, namely Whitten and Poppoff (1971), Banks and Kockarts (1973a), Banks and Kockarts (1973b), Brasseur and Solomon (1986), Tohmatsu (1990), and two books in French, Lilensten and Blelly (1999) and Kockarts (2000). There are many books dealing with aeronomy without mentioning this word in their title. Among those, three excellent books (Chamberlain and Hunten, 1987; Rees, 1989; Schunk and Nagy, 2000) will provide their readers with fundamental information. This does not imply that all other books are useless.

\section{What is the Lyman series?}

At the beginning of the $20^{\text {th }}$ Century, the development of quantum mechanics led quickly to the concept of energy levels in atomic spectra. Atomic hydrogen, the most simple element of the periodic table, could be treated analytically since this atom is composed of a single electron and a single proton. However, laboratory spectroscopy could not be done for wavelengths shorter than $125 \mathrm{~nm}$ since they are absorbed by fluorite $\mathrm{CaF}_{2}$. Lyman (1914), nevertheless, used a concave diffraction grating and discovered two lines, respectively, at $121.6 \mathrm{~nm}$ and $102.6 \mathrm{~nm}$ of a spectral series now called the Lyman-series. Figure 2 shows a Grotrian energy level diagram of the Lyman series. Wavelengths are taken from Wiese et al. (1966). It should be noted that a typographical error occurs in their Table A for the wavelength Lyman- $\gamma$, where $79.2537 \mathrm{~nm}$ should be read as $97.2537 \mathrm{~nm}$. The Lyman series is entirely in the far ultraviolet part of the solar spectrum and this radiation cannot reach the ground level as a consequence of atmospheric absorption. However, the solar Lyman- $\beta$ line can be absorbed by terrestrial hydrogen and through fluorescence and scattering can lead to emission of the $\mathrm{H} \alpha$ line, which is the first line of the Balmer series also shown on Fig. 2. This line at $656.3 \mathrm{~nm}$ is visible and can be observed from ground level. Herzberg (1927) made a detailed experimental study of the whole Balmer series and photographic plates XIII to XV can be seen at the end of volume 84 of Annalen der Physik. One plate is reproduced in Herzberg (1944). 
Anderson et al. (1987) used a spherical radiative transfer model to study the intensity and to deduce the hydrogen content independent of solar flux, as well as high-altitude distributions of atomic hydrogen. They noted a discrepancy of the order of a factor two between observed intensities and model results. This problem has been recently analyzed and solved by Bishop et al. (2001), using a nonisothermal Lyman- $\beta$ radiative transport code with updated Lyman- $\beta$ fluxes and corrected atomic hydrogen profiles in the thermosphere.

The fundamental mechanisms are rather simple and can be summarized as

$$
\begin{aligned}
& \mathrm{H}(1)+\mathrm{Ly}-\alpha \rightarrow \mathrm{H}(2) \rightarrow \mathrm{H}(1)+\mathrm{Ly}-\alpha \\
& \mathrm{H}(1)+\mathrm{Ly}-\beta \rightarrow \mathrm{H}(3) \rightarrow \mathrm{H}(1)+\mathrm{Ly}-\beta .
\end{aligned}
$$

These are two resonance mechanisms, since the absorbed wavelength is identical to the emitted wavelength. The numbers in parentheses indicate the energy levels shown on Fig. 2. Lyman $\beta$ can also lead to another mechanism

$$
\mathrm{H}(1)+\mathrm{Ly}-\beta \rightarrow \mathrm{H}(3) \rightarrow \mathrm{H}(2)+\mathrm{H}-\alpha .
$$

This is a fluorescence mechanism, since the emitted wavelength $(\mathrm{H}-\alpha)$ is longer than the absorbed wavelength (Ly- $\beta$ ). So there must be a branching ratio between process (2) and process (3). Bishop et al. (2001) used 0.12 for process (3) in their detailed analysis of the $\mathrm{H}-\alpha$ line.

\section{First observations and recent refinements}

The Lyman series is entirely in the far ultraviolet region of the solar spectrum. Therefore, it cannot be observed from ground level since stratospheric, mesospheric and thermospheric constituents are able to absorb it completely. This fact is illustrated in Fig. 3, which gives the altitude where unit optical depth is reached for two solar zenith angles as a function of wavelength. Such a figure is completely independent of the solar irradiance. It only depends on absorption cross sections and the abundances of the atmospheric species. One can see that Lyman- $\alpha$ deeply penetrates into the mesosphere as a result of the very low absorption cross section of molecular oxygen. Still, aeronomy had to wait for rocket experiments leading to measurements of solar radiation in the far ultraviolet.

The first solar spectrum below $340 \mathrm{~nm}$ was obtained by Baum et al. (1946) with a spectrograph mounted on a V-2 rocket. The rocket reached an altitude of $160 \mathrm{~km}$, but unfortunately, above $88 \mathrm{~km}$ the rocket turned the spectrograph away from the Sun. Although the instrument was capable of measuring down to $110 \mathrm{~nm}$, the obtained spectra showed lines between $340 \mathrm{~nm}$ and $210 \mathrm{~nm}$. Lyman- $\alpha$ could not be seen above $100 \mathrm{~km}$. This pioneering observation by the US Naval Research Laboratory opened the door for many other flights, which contributed significantly to our knowledge of the solar far ultraviolet region. Using a grazing-incident spectrograph mounted on an Aerobee rocket, Rense (1953) observed the solar Lyman- $\alpha$ line at an altitude of $81 \mathrm{~km}$. This

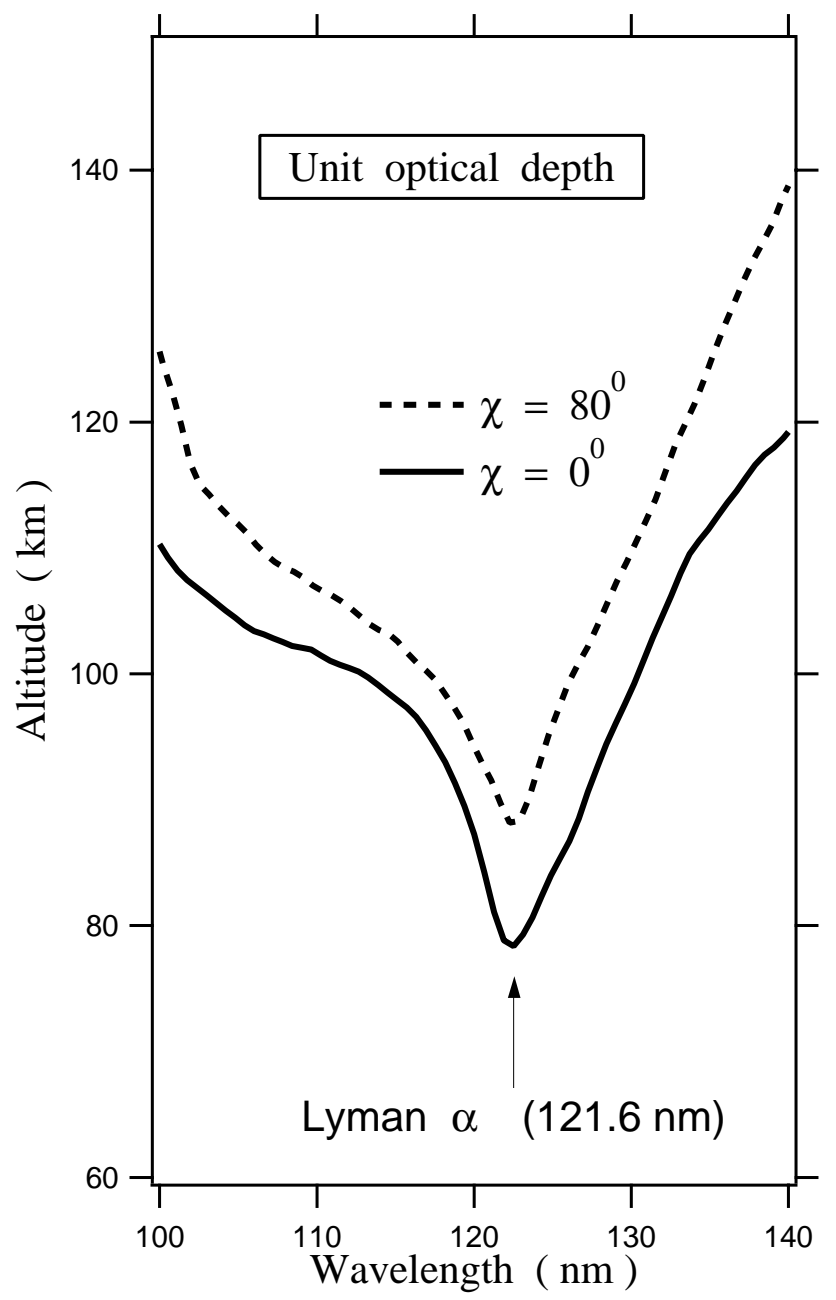

Fig. 3. Altitude where optical depth $\tau=1$ for solar zenith angles $\chi=0^{\circ}$ and $80^{\circ}$.

was the first experimental evidence that this radiation can penetrate in the ionospheric D-layer.

Tousey et al. (1964) observed the solar spectrum with two spectrographs on an Aerobee-Hi rocket launched on $22 \mathrm{Au}-$ gust 1962. One spectrograph covered the wavelength range 200 to $120 \mathrm{~nm}$ and the other one observed between 125 and $80 \mathrm{~nm}$. This flight led Tousey et al. (1965) to identify many lines in the spectrum. It is remarkable that 30 years later, Meier (1995) could use these photographic plates to reconstruct solar line profiles and line widths.

The experimental methods, based on film detection, were affected essentially by the high sensitivity to stray light, by the absence of time resolution and by the necessity for film recovery. These limitations were overcome by the use of photo-electric spectrometers (Hinteregger, 1960) for which data are telemetered to the ground level. This technique has been implemented on many satellites. As an example, Fig. 4 gives the irradiance measured by the Upper Atmosphere Research Satellite (UARS) on 28 February 1992 (London et al., 1993; Rottman, 1999). Several features can be seen in this figure. First, the solar Lyman- $\alpha$ line at $121.6 \mathrm{~nm}$ is by far 


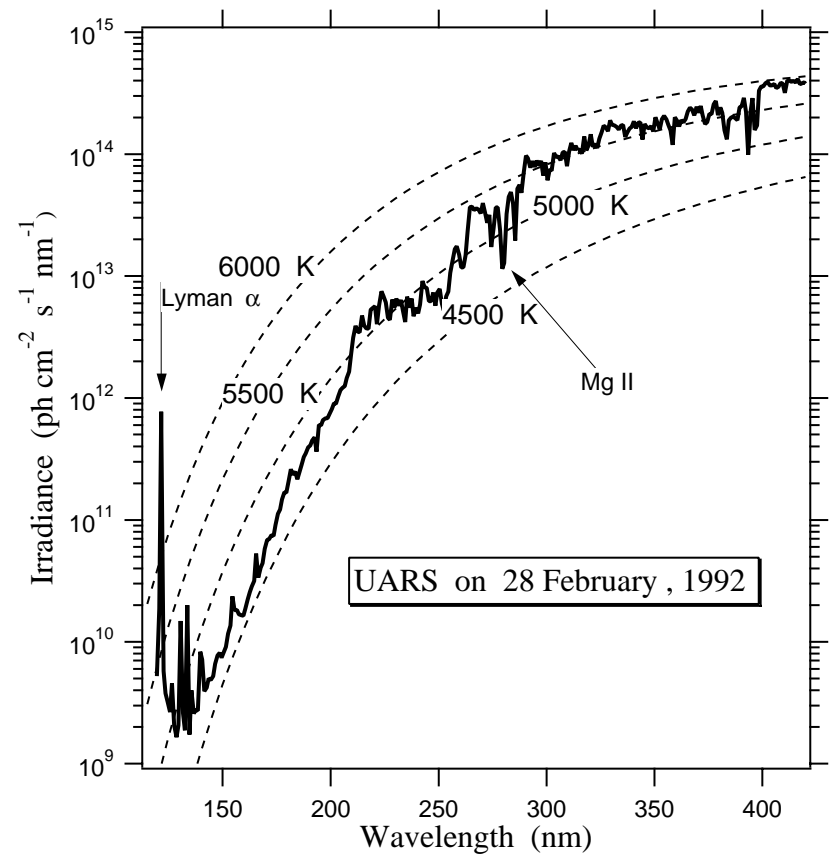

Fig. 4. Solar irradiance as a function of wavelength.

the most intense line in the EUV spectral range. Second, the magnesium doublet line $\mathrm{Mg}$ II, as absorption self-reversed lines around $280 \mathrm{~nm}$, is clearly seen. This doublet line is used to construct the Mg II index for modeling solar activity effects on the irradiance (Viereck and Puga, 1999) and Thuillier and Bruinsma (2001) showed that this index can also be used for semi-empirical atmospheric models instead of the usual $10.7 \mathrm{~cm}$ solar decimetric flux. Third, the dashed curves correspond to the irradiance computed for solar black body temperatures indicated on each curve. It is obvious that a single black body temperature cannot be used for wavelengths smaller than $400 \mathrm{~nm}$. Continuous space-borne measurements are, therefore, required to comprehend solar activity variations. While such an ideal situation cannot be obtained, several efforts have been made to model such effects. A huge project called SOLAR2000 is under development (Tobiska et al., 2000) to compute solar irradiance from $1 \mathrm{~nm}$ to $10^{6} \mathrm{~nm}$ for any level of solar activity. In their presentation, Tobiska et al. (2000) give all references for past, present and future data and models included in this semi-empirical model for solar irradiance. This ambitious program should extend to the year 2030. Figure 5 is computed with the model of Tobiska et al. (2000). It gives presently the daily solar irradiance from 1947 to 2000. Although it extends over periods where no measurements are available, it provides an efficient tool for studying solar activity effects. The 11-year solar cycle is clearly visible. Furthermore, at all solar minima, the daily solar irradiance is of the order of $3.5 \times 10^{11}$ photons $\mathrm{cm}^{-2} \mathrm{~s}^{-1}$. However, at solar maximum, the irradiance can be very different from one cycle to an other. Although there are many values for Lyman- $\alpha$ solar irradiance in Tobiska et al. (2000), only a few accurate profiles of this line are available.

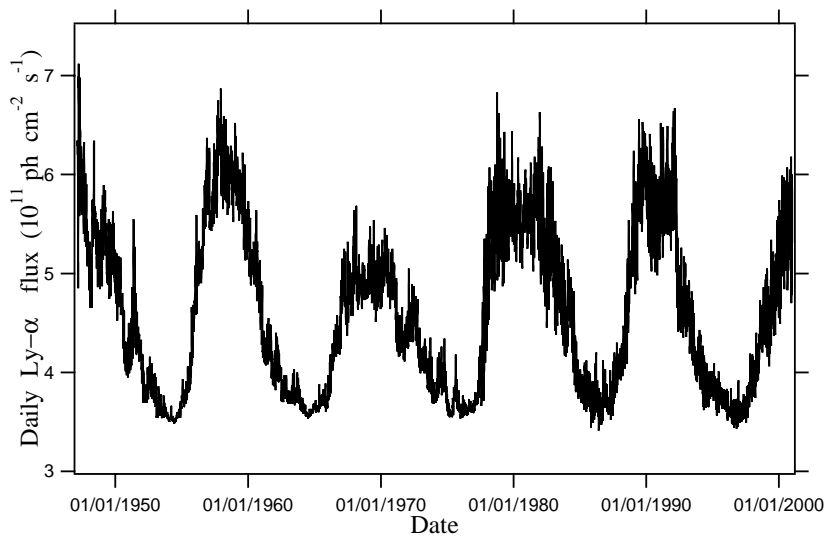

Fig. 5. Daily Lyman- $\alpha$ solar irradiance from 1947 to 2000.

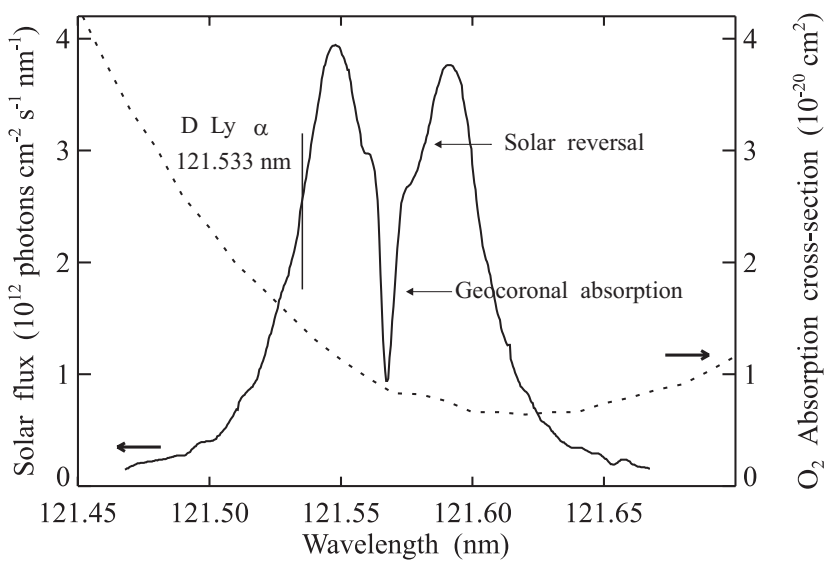

Fig. 6. Lyman- $\alpha$ profile (Lemaire et al., 1978) and $\mathrm{O}_{2}$ absorption cross Sect. (Lewis et al., 1983) for $203 \mathrm{~K}$.

Figure 6 shows such a profile measured by Lemaire et al. (1978), as well as the molecular oxygen absorption cross section measured by Lewis et al. (1983). One sees that adopting a constant cross section over the line width is not appropriate for aeronomy calculations. This problem has been discussed by Chabrillat and Kockarts (1997) with a parameterization of the line profile by three Gaussian functions. The consequences will be summarized in Sect. 4. However, the line profile in Fig. 6 corresponds to a minimum of solar activity for which the absolute values of Lemaire et al. (1978) have been rescaled to a total irradiance of $3 \times 10^{11}$ photons $\mathrm{cm}^{-2}$ $\mathrm{s}^{-1}$. Further measurements are still required to analyze the evolution of this profile with solar activity. Figure 6 indicates that the line profile has two components. One reflects the solar reversal resulting from atomic hydrogen in the solar atmosphere, the other corresponds to geocoronal absorption by terrestrial atomic hydrogen. The position of the deuterium Lyman- $\alpha$ line falls on the blue wing of the atomic hydrogen line. This line is, therefore, extremely difficult to detect with conventional spectrometers. 


\section{Implications for atmospheric neutral physics and chemistry}

The presence of the deep minimum in the Lyman- $\alpha$ line profile shown on Fig. 6 is a clear proof that atomic hydrogen should play a significant role in the terrestrial atmosphere. The question is to know where that atomic hydrogen comes from. Figure 1 shows no atomic hydrogen, since Chapman and Milne (1920) did not consider photochemical reactions in their model.

\subsection{Contribution of aeronomy to atmospheric photochem- istry}

However, Chapman (1930) published his famous mechanism for the formation of ozone $\mathrm{O}_{3}$ corresponding to the following processes. First, a photodissociation of molecular oxygen for wavelengths shorter than $242.4 \mathrm{~nm}$

$\mathrm{O}_{2}+\mathrm{h} v \rightarrow \mathrm{O}+\mathrm{O} \quad$ coefficient $\quad \mathrm{J}_{2} \quad\left(\mathrm{~s}^{-1}\right)$

allows for ozone to be formed by the reaction

$\mathrm{O}_{2}+\mathrm{O}+\mathrm{M} \rightarrow \mathrm{O}_{3}+\mathrm{M} \quad \mathrm{k}_{1} \quad\left(\mathrm{~cm}^{6} \mathrm{~s}^{-1}\right)$.

In the lower thermosphere atomic oxygen becomes important and the three-body reaction

$\mathrm{O}+\mathrm{O}+\mathrm{M} \rightarrow \mathrm{O}_{2}+\mathrm{M} \quad \mathrm{k}_{2} \quad\left(\mathrm{~cm}^{6} \mathrm{~s}^{-1}\right)$

is then able to compete with ozone formation.

Ozone can also be photodissociated in the UV, visible and infrared part of the solar spectrum

$\mathrm{O}_{3}+\mathrm{h} v \rightarrow \mathrm{O}_{2}+\mathrm{O} \quad$ coefficient $\quad \mathrm{J}_{3} \quad\left(\mathrm{~s}^{-1}\right)$

or it can react with atomic oxygen

$\mathrm{O}_{3}+\mathrm{O}+\mathrm{M} \rightarrow 2 \mathrm{O}_{2}+\mathrm{M} \quad \mathrm{k}_{3} \quad\left(\mathrm{~cm}^{3} \mathrm{~s}^{-1}\right)$.

The Chapman mechanism is presently included in any atmospheric model dealing with chemistry. Although the rate coefficients were not available at the time of the paper by Chapman (1930), they can be found in compilations like DeMore et al. (1997). This critical evaluation of hundreds of reactions is a clear indication of the impact given by aeronomy to laboratory studies.

Photodissociation absorption cross sections are also required to implement Chapman's mechanism in an atmospheric model. As an example, Fig. 7 shows absorption cross sections for the principal constituents attenuating the incoming solar radiation. One should note that ozone can be photodissociated over the whole spectral range, including the visible and infrared part in the Chappuis bands. Molecular oxygen can only be photodissociated for wavelengths shorter than $242.4 \mathrm{~nm}$ and it is photoionized for wavelengths shorter than $102.7 \mathrm{~nm}$. Although it is a major constituent, molecular nitrogen does not appear in Fig. 7, since it is almost transparent in the whole spectrum. But it can be ionized for wavelengths shorter than $79.6 \mathrm{~nm}$. On the upper part of Fig. 7, two
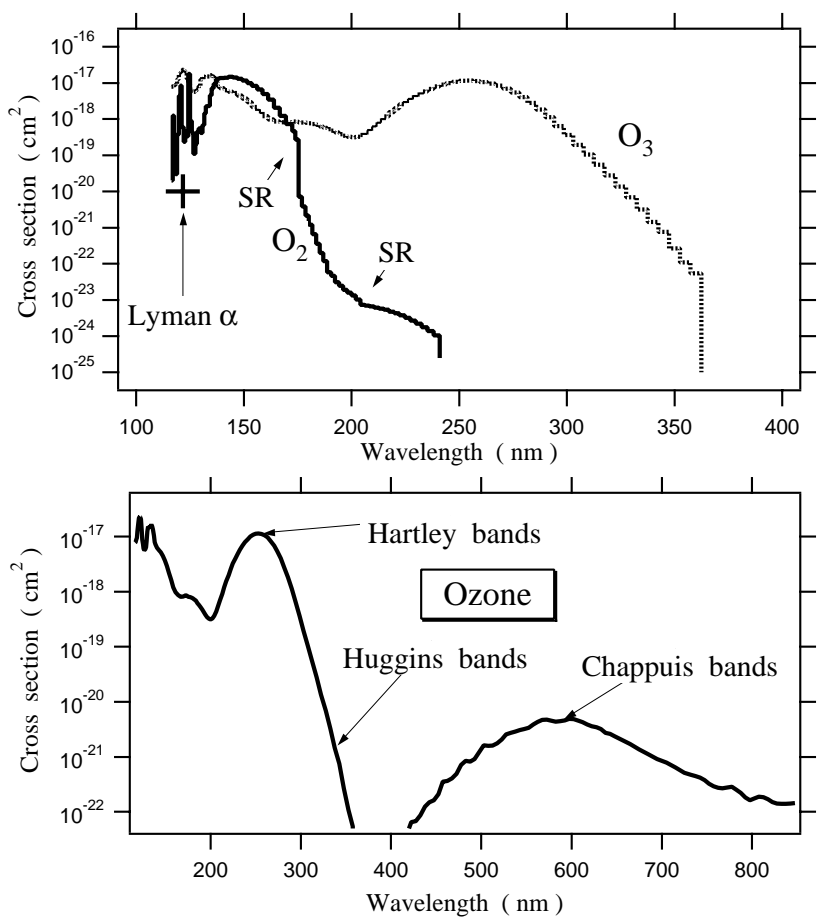

Fig. 7. Photodissociation cross section for $\mathrm{O}_{2}$ and $\mathrm{O}_{3}$.

oblique arrows labeled SR show the extent of the SchumannRunge bands from $204 \mathrm{~nm}$ down to $175 \mathrm{~nm}$. The cross section is highly variable as a function of wavelength and temperature, and the values shown in Fig. 7 are only indicative. Numerical approximations have been developed by Kockarts (1994), but they should not be used for computing NO photodissociation, since this minor constituent is characterized by numerous absorption lines in the wavelength region of the Schumann-Runge bands. Minschwaner and Siskind (1993) have developed a specific approximation for this case. It should be noted that their subdivision of the solar spectrum in small intervals does not correspond to the usually adopted intervals of $500 \mathrm{~cm}^{-1}$. Another binning of the solar irradiances is, therefore, required.

The position of our guide, the solar Lyman- $\alpha$ line, is also indicated in Fig. 7 with a constant photodissociation cross section of $10^{-20} \mathrm{~cm}^{2}$. As noted earlier, use of such a constant cross section should be definitely abandoned (Chabrillat and Kockarts, 1997), since it can lead to an underestimation of the order of $20 \%$ for $\mathrm{H}_{2} \mathrm{O}$ photodissociation in the lower mesosphere and more than $50 \%$ for $\mathrm{CH}_{4}$ photodissociation.

Depending on the value of the cross section and of the wavelength, the photodissociation products can be in their ground state or in an excited state. Sometimes quantum yields, which can even be temperature dependent (DeMore et al., 1997), play a significant role. In particular, production of excited $\mathrm{O}\left({ }^{1} \mathrm{D}\right)$ atoms can lead to chemical reactions which are negligible with atomic oxygen in its ground state $\mathrm{O}\left({ }^{3} \mathrm{P}\right)$. Lacoursière et al. (1999) measured and calculated the quantum yield for $\mathrm{O}\left({ }^{1} \mathrm{D}\right)$ when molecular oxygen is photodissociated by Lyman- $\alpha$. Their results shows that the quantum yield 

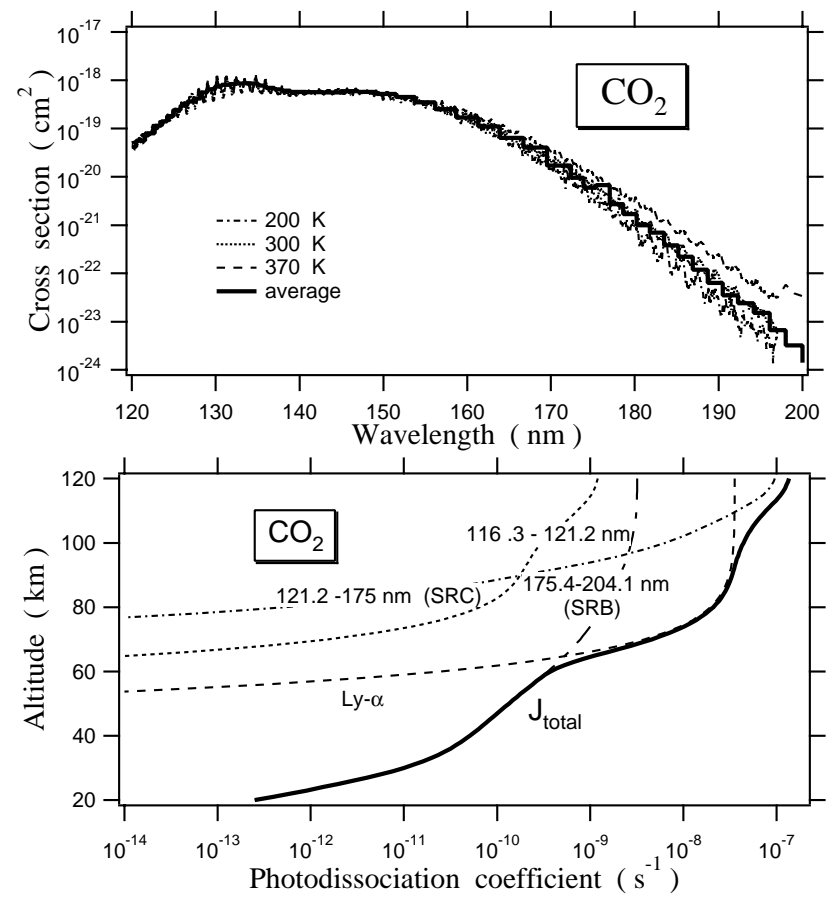

Fig. 8. Absorption cross section and photodissociation coefficient for $\mathrm{CO}_{2}$.

varies over the line profile with a weighted mean quantum yield of $0.58 \pm 0.06$. These results are a confirmation of the necessity to take the line profile into account, as it has been done by Chabrillat and Kockarts (1997).

Photodissociation computations require a good knowledge of the absorption cross sections which can be temperature dependendent. As an example, the upper panel of Fig. 8 shows the absorption cross section for carbon dioxide measured by Lewis and Carver (1983) for three temperatures. The curve labelled "average" has been used to compute the $\mathrm{CO}_{2}$ photodissociation coefficient in various spectral ranges indicated in the lower panel of Fig. 8. One sees that Lyman- $\alpha$ gives the major contribution in the mesosphere and that the SchumannRunge bands (SRB) are the only wavelength region acting for a dissociation of $\mathrm{CO}_{2}$ in the stratosphere. The SchumannRunge continuum (SRC) provides the major contribution in the thermosphere. These computations are made for an overhead Sun. The distribution of $\mathrm{CO}_{2}$ in the middle atmosphere is determined by molecular diffusion (see next subsection), rather than by its loss through photodissoiation (Chabrillat, 2001). This process, nevertheless, should be accurately computed, taking into account the Lyman- $\alpha$ solar profile and the temperature dependence of the $\mathrm{CO}_{2}$ cross section, since this photodissociation is the only source of $\mathrm{CO}$ in the middle atmosphere.

Bates and Nicolet (1950) introduced the effect of hydroxyl radicals by considering photodissociation of water vapor

$\mathrm{H}_{2} \mathrm{O}+\mathrm{h} v \rightarrow \mathrm{H}+\mathrm{OH}$.
Although other channels are energetically possible below $200 \mathrm{~nm}$, Slanger and Black (1982) showed that Eq. (9) is the predominant channel at Lyman- $\alpha$. Lewis et al. (1983) made accurate measurements of the $\mathrm{O}_{2}$ and $\mathrm{H}_{2} \mathrm{O}$ absorption cross sections, indicating that for molecular oxygen the cross section is temperature dependent but not for water vapor. This dependency is included in the parameterization developed by Chabrillat and Kockarts (1997).

Once water vapor is photodissociated, Bates and Nicolet (1950) considered the effect of the hydroxyl radicals. In particular, the following two reactions are a catalytic mechanism for ozone destruction

$\mathrm{H}+\mathrm{O}_{3} \rightarrow \mathrm{OH}(v \leq 9)+\mathrm{O}_{2}$

and

$\mathrm{OH}+\mathrm{O} \rightarrow \mathrm{O}_{2}+\mathrm{H}$

with a net result

$\mathrm{O}_{3}+\mathrm{O} \rightarrow \mathrm{O}_{2}+\mathrm{O}_{2}$.

The $\mathrm{OH}$ radical produced by reaction (11) can be in a vibrationaly excited state up to vibrational level $v=9$. This excited $\mathrm{OH}$ leads to the Meinel bands for which the strongest bands appear around $1.5 \mu \mathrm{m}$ for $\Delta v=2$. The intensity for these transitions can reach $10^{5}$ Rayleigh (Chamberlain and Hunten, 1987). One Rayleigh corresponds to an omnidirectional emission rate of $10^{6}$ photons $\mathrm{cm}^{-2} \mathrm{~s}^{-1}$ in a column of unit cross section along the line of sight.

\subsection{Contribution of aeronomy to transport phenomena}

Once atomic hydrogen is produced by photodissociation of water vapor and to a lesser extent of methane, the only way to increase its abundance with height must be due to transport. All atmospheric constituents can be transported by global phenomena, such as winds, advection and convection. These global phenomena are usually treated with hydrodynamic equations (Holton, 1972, 1975; Houghton, 1977; Peixoto and Oort, 1992).

When specific movements are considered for each constituent, one has to use conservation equations based on gas kinetic theory (Chapman and Cowling, 1952; Hirschfelder et al., 1954). The transport velocity $\boldsymbol{w}_{\boldsymbol{i}}$ for a constituent $i$ can be split into three terms

$w_{i}=v_{i D}+v_{i K}+v$,

where $\boldsymbol{v}_{\boldsymbol{i} \boldsymbol{D}}$ is the molecular diffusion component, $\boldsymbol{v}_{\boldsymbol{i} \boldsymbol{K}}$ is the turbulent diffusion component and $v$ is the global transport component which can be obtained from hydrodynamic equations. The first two components result from gas kinetic theory. They are often neglected in climatological models.

In order to compute the concentration $n_{i}$ of a constituent $i$, it is necessary to introduce the transport velocity $\boldsymbol{w}_{\boldsymbol{i}}$ in the continuity equation

$\frac{\partial n_{i}}{\partial t}+\operatorname{div}\left(n_{i} \boldsymbol{w}_{i}\right)=P_{i}-L_{i}$, 
where $t$ represents time and $P_{i}, L_{i}$ are, respectively, the chemical production and loss rates in $\mathrm{cm}^{-3} \mathrm{~s}^{-1}$ for constituent $i$. Eqation (14) is suitable to see how atomic hydrogen can become an important constituent in the terrestrial atmosphere. For reasons of simplicity it will be used in its scalar, one-dimensional form along the vertical axis.

From gas kinetic theory (Chapman and Cowling, 1952), it can be shown that the vertical component of the molecular diffusion velocity $v_{i D}$ is given by

$v_{i D}=-D_{i} \times\left(\frac{1}{n_{i}} \frac{\partial n_{i}}{\partial z}+\frac{1}{H_{i}}+\frac{1+\alpha_{i}}{T} \frac{\partial T}{\partial z}\right)$,

where $T$ is the temperature at altitude $z, n_{i}$ is the concentration and $H_{i}=k T / m_{i} g$ is the scale height associated with the partial pressure of constituent $i, \alpha_{i}$ is the dimensionless thermal diffusion factor ( -0.38 for atomic hydrogen) and $D_{i}$ is the molecular diffusion coefficient in $\mathrm{cm}^{2} \mathrm{~s}^{-1}$.

The molecular diffusion coefficient is often measured (Mason and Marrero, 1970) and can be expressed under the form

$D_{i}=\frac{A_{i} \times T^{s}}{n}$,

where $A_{i}$ is a constant, $s$ is of the order of 0.7 and $n$ is the total concentration. When there are no measurements for the molecular diffusion coefficient, it can be estimated from gas kinetic theory, assuming that the molecules behave like billiard balls with specular reflection. An expression is given by Banks and Kockarts (1973b) as

$D_{i}=1.52 \times 10^{18}\left(\frac{1}{M_{i}}+\frac{1}{M}\right)^{1 / 2} \times \frac{T^{1 / 2}}{n}$,

where $M_{i}$ and $M$ are, respectively, the mass of the minor constituent $i$ and the mean molecular mass in atomic mass units.

Using Eq. (15) and assuming there is a constant escape flux at the beginning of the exosphere, one obtains vertical hydrogen distributions of the type shown in Fig. 9 (Kockarts and Nicolet, 1962,1963) The dashed lines on Fig. 9 show the corresponding diffusive equilibrium when $v_{i D}$ is set to zero in Eq. (15). Two important features can be noted in Fig. 9: below $200 \mathrm{~km}$ the distributions tend towards a mixing distribution and at greater heights the concentrations are smaller when temperature increases. These are consequences of the transport equation with a constant escape flux. No chemistry is introduced in the results of Fig. 9 and at $100 \mathrm{~km}$ the concentration has been arbitrarily taken equal to $10^{7} \mathrm{~cm}^{-3}$. Liu and Donahue (1974) made an important contribution to the problem by computing the vertical distributions from $50 \mathrm{~km}$ altitude up to the beginning of the exosphere. Their results considered chemical reactions and showed that molecular hydrogen $\mathrm{H}_{2}$ can reach concentrations greater than $\mathrm{H}$ around $100 \mathrm{~km}$. Hunten and Strobel (1974) have also addressed the question in a slightly different manner, but reached similar conclusions. It should be noted that the major production mechanism for molecular hydrogen is the reaction

$\mathrm{H}+\mathrm{HO}_{2} \rightarrow \mathrm{H}_{2}+\mathrm{O}_{2}+57 \mathrm{kcal}$,

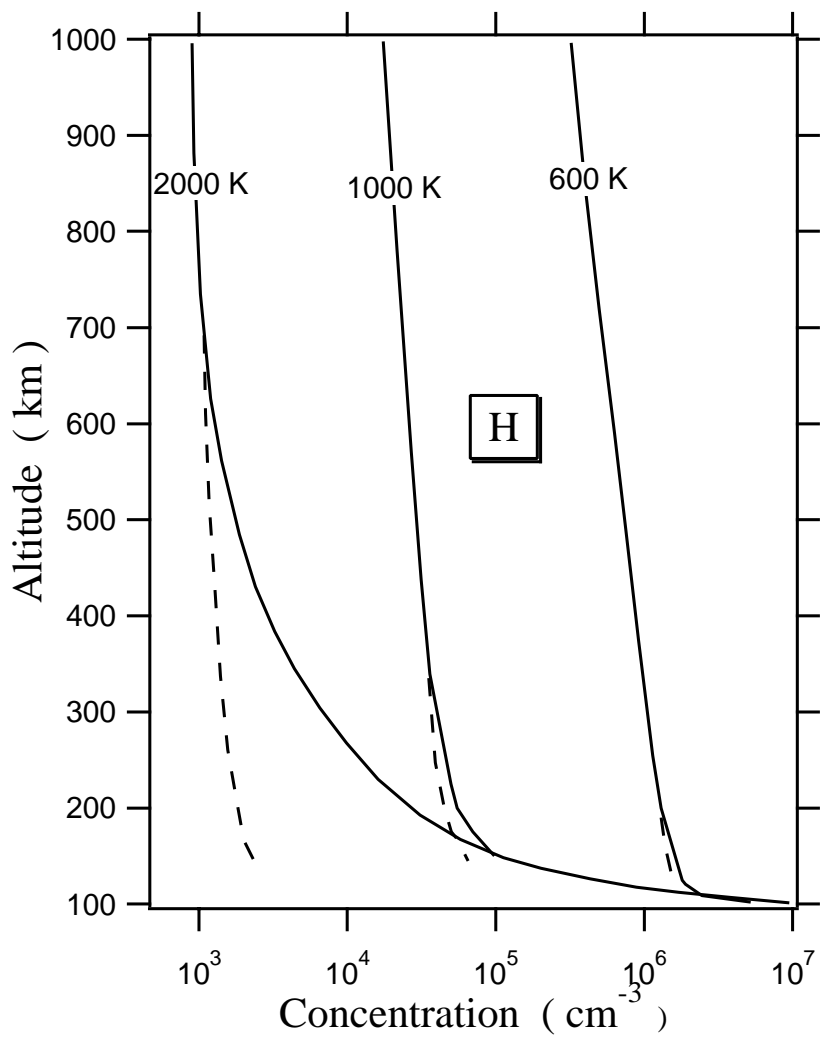

Fig. 9. Atomic hydrogen vertical distributions for three thermopause temperature.

which is a loss for atomic hydrogen. The major chemical loss mechanism for molecular hydrogen is

$\mathrm{H}_{2}+\mathrm{O}\left({ }^{1} \mathrm{D}\right) \rightarrow \mathrm{H}+\mathrm{OH}(v \leq 4)+43 \mathrm{kcal}$.

The turbulent diffusion velocity in Eq. (13) cannot be evaluated from gas kinetic theory, but by analogy with Eq. (15), one can write for each constituent $i$

$v_{i K}=-\frac{K}{f_{i}} \frac{\partial f_{i}}{\partial z}=-K \times\left(\frac{1}{n_{i}} \frac{\partial n_{i}}{\partial z}+\frac{1}{H}+\frac{1}{T} \frac{\partial T}{\partial z}\right)$,

where $f_{i}=n_{i} / n$ is the volume mixing ratio of constituent $i$ and $H=k T / m g$ is the atmospheric scale height associated with the total pressure. There exists no analytical expression derived from turbulent theory for the coefficient $K$ in $\mathrm{cm}^{2} \mathrm{~s}^{-1}$. This quantity must be estimated, either from measured vertical distributions of chemically inert constituents, or from parameterizations of gravity wave dissipation (Lindzen, 1981; Hines, 1997, 1999).

In the absence of photochemical reactions, a constituent $i$ is either in perfect mixing $\left(v_{i K}=0\right)$ or in diffusive equilibrium $\left(v_{i D}=0\right)$.

If we assume that the vertical distribution of constituent $i$ is in perfect mixing, i.e. $\partial n_{i} /\left(n_{i} \partial z\right)=-(1 / H)-$ $(1 / T)(\partial T / \partial z)$, then the maximum molecular diffusion velocity given by Eq. (15) is

$v_{i D \max }=+\frac{D_{i}}{H}\left[1-\frac{H}{H_{i}}-\frac{\alpha_{i} H}{T} \frac{\partial T}{\partial z}\right]$. 
Similarly, if constitutent $n_{i}$ is in diffusive equilibrium, i.e. $\left.\partial n_{i} /\left(n_{i} \partial z\right)=-\left(1 / H_{i}\right)-\left[\left(1+\alpha_{i}\right) / T\right)\right](\partial T / \partial z)$, then the maximum turbulent transport velocity given by Eq. (20) is

$v_{i K \max }=-\frac{K}{H}\left[1-\frac{H}{H_{i}}-\frac{\alpha_{i} H}{T} \frac{\partial T}{\partial z}\right]$.

These velocities are of opposite sign and are equal in absolute value when $D_{i}=K$. When these velocities are multiplied by the concentration, one obtains the maximum transport flux. Hunten (1975) called this quantity "limiting flow". Some authors (Yung et al., 1989) even consider this expression as "Hunten's limiting flux theorem". It should be noted that maximum transport velocities are a permanent physical characteristic for a given constituent, since only the nature of the constituent is to be considered. The limiting flow, however, is a characteristic for a given mixing ratio and it can change if there are modifications in the abundance of the constituent. Kockarts (1972a) derived from the continuity equation a general expression for the vertical differential equation of a minor constituent, subject simultaneously to molecular and turbulent transport. This equation can be integrated analytically.

Experimental derivation of atomic hydrogen concentration is presently possible with two techniques, one based on ionospheric observations and the second one from optical Lyman$\alpha$ airglow. Although atomic hydrogen is difficult to measure by mass spectrometers, it is possible to measure $\mathrm{H}^{+}, \mathrm{O}^{+}$and $\mathrm{O}$. Since $\mathrm{H}$ and $\mathrm{O}$ have practically the same ionization potential, charge exchange equilibrium is applicable in the Fregion, i.e.

$\mathrm{H}+\mathrm{O}^{+} \rightleftharpoons \mathrm{H}^{+}+\mathrm{O}$.

For equal neutral temperature and ion temperature, the equilibrium is expressed by

$\frac{n(\mathrm{H})}{n(\mathrm{O})}=\frac{8}{9} \frac{n\left(\mathrm{H}^{+}\right)}{n\left(\mathrm{O}^{+}\right)}$.

When the two temperatures are not equal, Banks (1968) gives the appropriate expression. Using mass spectrometric data obtained by Atmospheric explorer C in 1974, Breig et al. (1976) determined the neutral concentrations for atomic hydrogen.

The interpretation of optical observations requires the calculation of model hydrogen atmospheres, since it is the total content along the line of sight which is actually observed. A good review of the state of the art for observations before 1974 is given by Tinsley (1974). Using a spherical geometry radiative transfer model (Bishop, 1999), observed Lyman- $\alpha$ disk-to-limb intensities are analyzed by Bishop (2001) to deduce hydrogen profiles between $74 \mathrm{~km}$ and $470 \mathrm{~km}$. In this way he could also determine the peak concentration for $\mathrm{H}$ in the mesosphere below $100 \mathrm{~km}$ altitude. This approach is very promising, since semi-empirical atmospheric models (Hedin, 1987, 1991; Berger et al., 1998) use essentially the charge exchange equilibrium (Eq. (24)) to introduce atomic hydrogen in the models. The atomic hydrogen profiles below the F-region do not contain experimental values.
Table 1. Ionization limits

\begin{tabular}{cccccc}
\hline Species & $\mathrm{O}_{2}$ & $\mathrm{H}$ & $\mathrm{O}$ & $\mathrm{N}_{2}$ & $\mathrm{He}$ \\
$\lambda(\mathrm{nm})$ & 102.7 & 91.1 & 91 & 79.6 & 50.4 \\
\hline
\end{tabular}

The position of the deuterium Lyman- $\alpha$ line at $121.533 \mathrm{~nm}$ indicated in Fig. 6 shows that this line should be extremely difficult to detect since it is on the blue wing of the hydrogen Lyman- $\alpha$ line in a region of steep spectral gradient. Furthermore, the isotopic ratio $n(\mathrm{D}) / n(\mathrm{H})$ is only $1.6 \times 10^{-4}$ in standard mean ocean water. Breig et al. (1987) deduced D/H ratios from Atmospheric Explorer $\mathrm{C}$ ion measurements and arrived at an agreement with previous theoretical work (Kockarts, 1972b). The problem was revisited by Breig and Hanson (1991). The first optical detection of atomic deuterium was obtained by Bertaux et al. (1984a, 1984b). This detection, looking at the limb at $110 \mathrm{~km}$, was made possible by using hydrogen and deuterium cells developed at the Service d'Aéronomie in France. A similar instrument, but with a much higher sensitivity, was flown on the ATLAS 1 mission in 1992 (Bertaux et al., 1993). Using observations of Mars between 121.2 and $121.8 \mathrm{~nm}$ obtained with the Hubble Space Telescope, Krasnopolsky (1998) constructed a model for terrestrial deuterium, since the spectrum showed the deuterium Lyman- $\alpha$ line both on Mars and on Earth.

\section{Implications for atmospheric ion chemistry}

All planetary ionospheres result essentially from the interaction of the neutral atmosphere and solar radiation. In some cases, cosmic rays and particle precipitations also play a role. Each neutral constituent has an ionization potential which determines the longest ionizing wavelength. For the terrestrial atmosphere, the ionization limits of the constituents are given in Table 1. This table indicates that the ionosphere essentially comes from the solar spectrum below $100 \mathrm{~nm}$ and apparently Lyman- $\alpha$ should play no role in the formation of the terrestrial ionosphere. For those wavelengths, Richards et al. (1994) established a solar EUV flux model and gave the absorption and ionization cross sections for $\mathrm{O}_{2}, \mathrm{~N}_{2}, \mathrm{O}$ and $\mathrm{N}$ between 100 and $5 \mathrm{~nm}$.

On the other hand, Nicolet and Aikin (1960) showed that the direct ionization of nitric oxide NO by Lyman- $\alpha$ leads to an important contribution to the formation of the terrestrial D-region below $100 \mathrm{~km}$ altitude. They also showed that $\mathrm{X}$ rays of $\lambda \leq 1 \mathrm{~nm}$ significantly ionize molecular nitrogen and oxygen below $85 \mathrm{~km}$. Wavelengths greater than $180 \mathrm{~nm}$ can also ionize various minor constituent atoms, such as sodium and calcium. Later, Hunten and McElroy (1968) showed that the excited state $\mathrm{O}_{2}\left(a^{1} \Delta_{g}\right)$ can be ionized by the wavelength band $102.7-111.8 \mathrm{~nm}$ and in such a way it can produce $\mathrm{O}_{2}^{+}$ ions below $70 \mathrm{~km}$. Ionization of NO by Lyman- $\alpha$ and of $\mathrm{O}_{2}\left(a^{1} \Delta_{g}\right)$ are presently two important processes introduced in any ionospheric model of the D-region. 


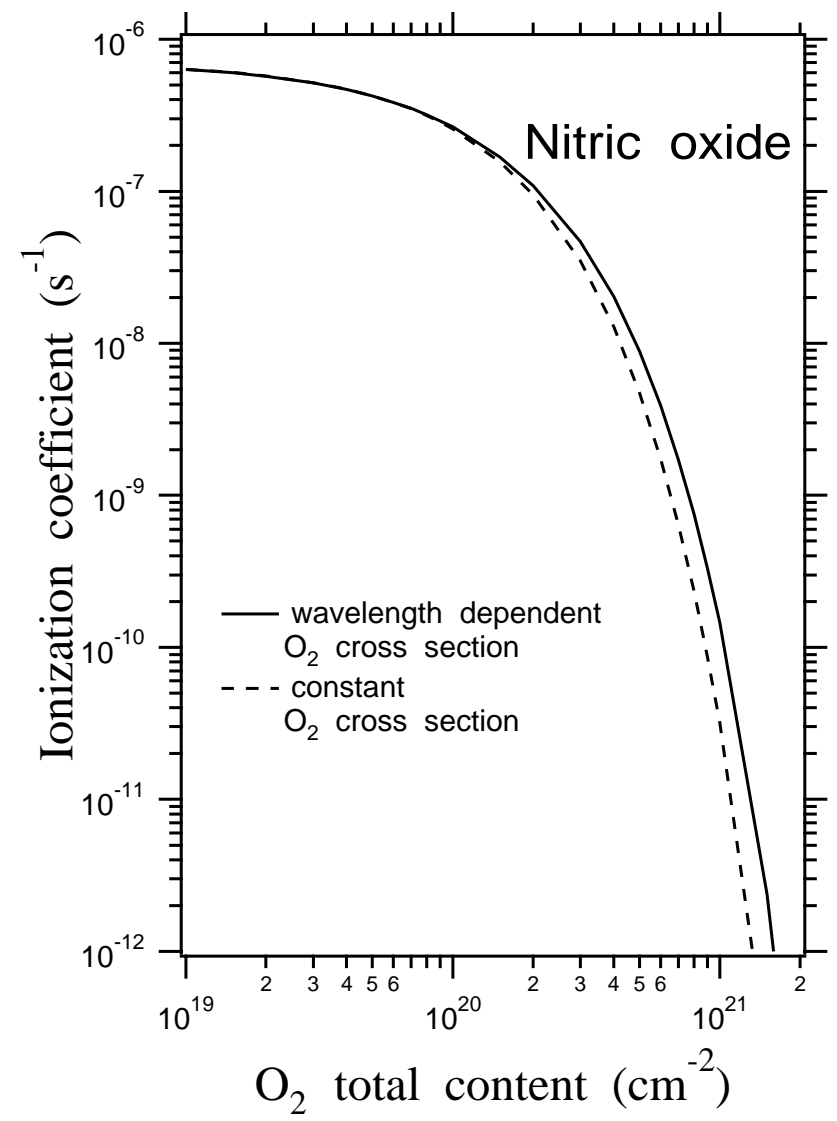

Fig. 10. Nitric oxide ionization coefficient as a function of $\mathrm{O}_{2}$ total content (see text for an explanation of the two curves).

Therefore, it is necessary to evaluate the ionization coefficient of $\mathrm{NO}$ as a function of the $\mathrm{O}_{2}$ total content along the line of sight. The results are shown in Fig. 10. The dashed curve is computed with a constant absorption cross section of $10^{-20} \mathrm{~cm}^{2}$ for $\mathrm{O}_{2}$ at Lyman- $\alpha$ (Brasseur and Solomon, 1986). However, Fig. 6 shows that the $\mathrm{O}_{2}$ absorption cross section cannot be considered as constant over the profile of Lyman- $\alpha$. Therefore, the full curve is computed with the reduction factors developped by Chabrillat and Kockarts (1997) for minor constituents. The ionization coefficient $I_{N O}$ can be written as

$I_{N O}=\phi_{\infty L y \alpha} \times \sigma_{i} \times R_{M}(z)$,

where $\sigma_{i}=2 \times 10^{-18} \mathrm{~cm}^{2}$ is the NO ionization cross section at Lyman- $\alpha$. In the present computation, the Lyman- $\alpha$ flux at the top of the atmosphere is $\phi_{\infty L y \alpha}=3.5 \times 10^{11}$ photons $\mathrm{cm}^{-2} \mathrm{~s}^{-1}$. The reduction factor $R_{M}(z)$ is given by the following expression

$R_{M}(z)=\sum_{i=1}^{3} b_{i} \times \exp \left(-c_{i} \times N_{O_{2}}(z)\right)$.

In this expression, $N_{O_{2}}(z)$ is the total content of molecular oxygen. The numerical coefficients in Eq. (26) are given in Table 2.

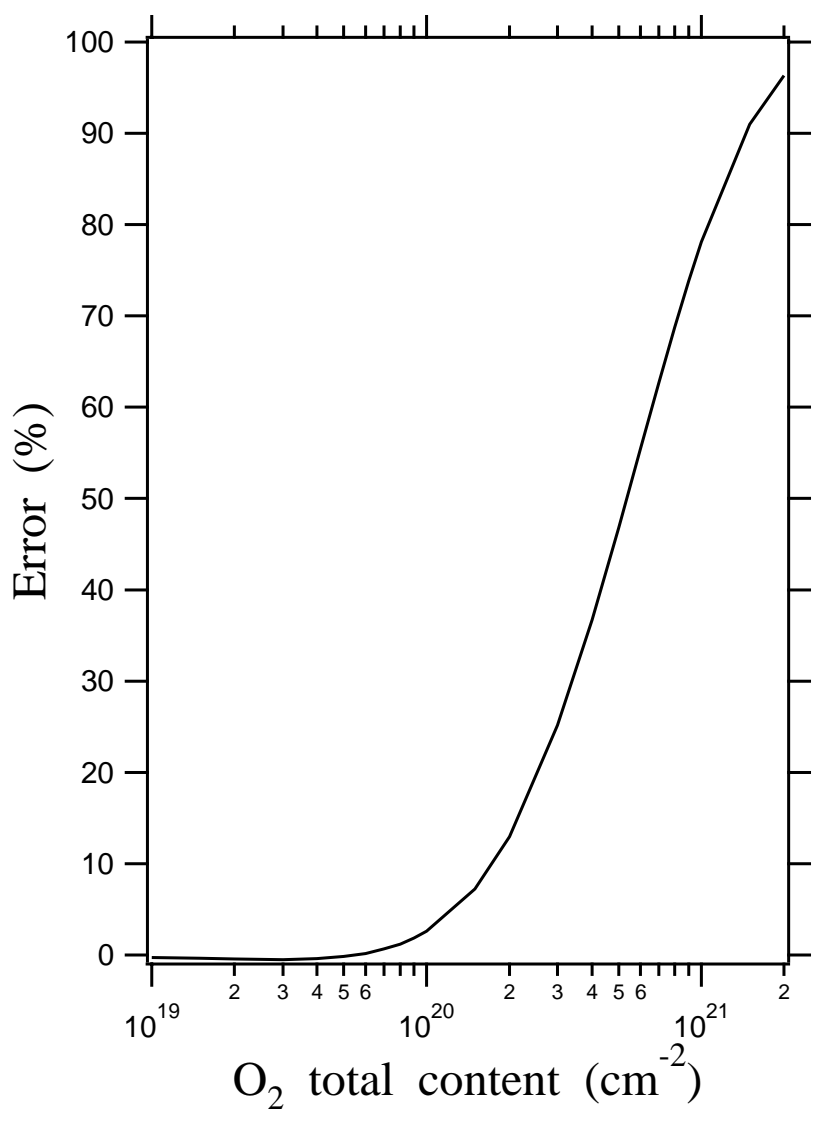

Fig. 11. Error introduced by the use of a constant $\mathrm{O}_{2}$ absorption cross section.

Table 2. Parameters for the reduction factor $R_{M}(z)$

\begin{tabular}{ccc}
\hline$i$ & $b_{i}$ & $c_{i}$ \\
\hline 1 & 0.6843100 & $8.22114 \times 10^{-21}$ \\
2 & 0.2298441 & $1.77556 \times 10^{-20}$ \\
3 & 0.0865412 & $8.22112 \times 10^{-21}$ \\
\hline
\end{tabular}

One can see that the error introduced by a constant absorption cross section for $\mathrm{O}_{2}$ increases with the total content. This error is defined by

Error $=100 \times\left(\mathrm{I}_{\mathrm{NO}}^{\text {exact }}-\mathrm{I}_{\mathrm{NO}}^{\text {approx }}\right) / \mathrm{I}_{\mathrm{NO}}^{\text {exact }}$,

where the labels "exact" and "approx" correspond, respectively, to computations with the reduction factors and with a constant $\mathrm{O}_{2}$ absorption cross section.

Figure 11 clearly shows that the technique of the reduction factors should always be used for the absorption of Lyman- $\alpha$.

\section{Implications for exospheric physics}

Since the total concentration decreases exponentially with height, there must be a region where collisions become negligible; this is the exosphere. A good way to determine its 


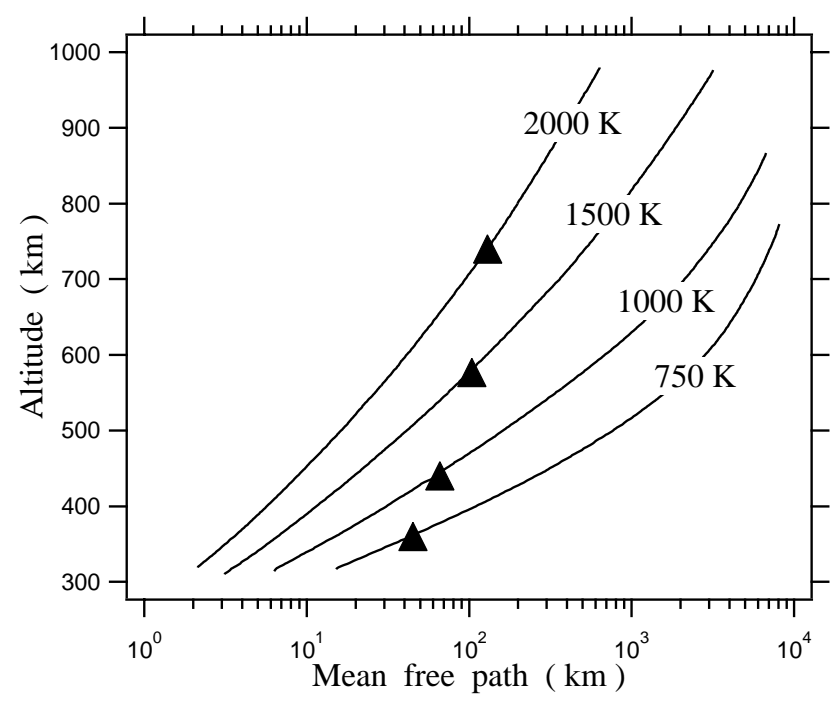

Fig. 12. Vertical distribution of the mean free path for several thermopause temperatures. The triangles give the altitude where the mean free path is equal to the atmospheric scale height.

lower boundary is to compute the mean free path as a function of altitude and for different thermopause temperatures. Figure 12 shows the results of such a computation. The mean free path at ground level is of the order of $6 \times 10^{-6} \mathrm{~cm}$ and in the exosphere, it can reach several hundreds or thousands $\mathrm{km}$. A common definition of the beginning of the exosphere, often called "critical level", is the altitude where the horizontal mean free path is equal to the atmospheric scale height. The critical level is, therefore, indicated by the triangle in Fig. 12.

In such a collisionless medium, which types of particles are possible? Considering an elementary volume above the critical level, four types of particles, shown in Fig. 13, are theoretically possible:

- ballistic particles, with a volume abundance $\varphi_{1}$, which are launched from a point at the critical level and fall back at another point;

- satellite particles, with a volume abundance $\varphi_{2}$, which flow around the Earth like a satellite;

- hyperbolic particles, with a volume abundance $\varphi_{3}$, which leave the critical level with a velocity $\geq 11 \mathrm{~km}$ $\mathrm{s}^{-1}$, which come from interplanetary space and are sufficient to overcome gravitational attraction;

- external hyperbolic particles, with a volume abundance $\varphi_{4}$, which come from interplanetary space and are deviated by the Earth's gravitational field.

If the velocity distribution function is Maxwellian in the exosphere, i.e. a solution of Boltzmann's equation without collisions, one has the relation

$\varphi_{1}+\varphi_{2}+\varphi_{3}+\varphi_{4}=1$.

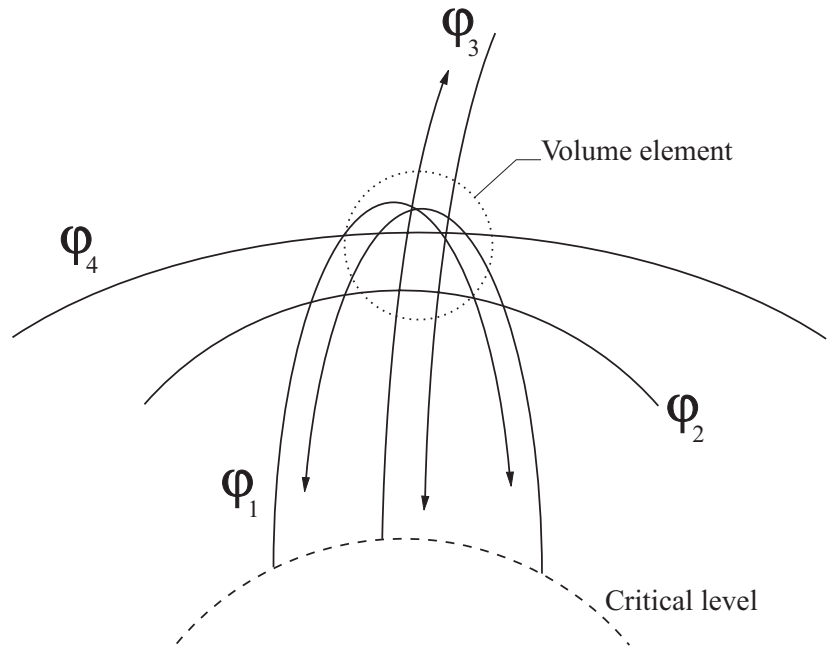

Fig. 13. Exospheric particles.

The vertical distribution of a constituent like atomic hydrogen would then be a hydrostatic distribution, implying a nonzero density at infinity. It is easy to see that this is not the case.

For the ballistic particles $\varphi_{1}$, the heterosphere should have a perfect spherical symmetry. This is not realistic, since there are diurnal and seasonal variations.

For the satellite particles $\varphi_{2}$, no external action should be present. This is not the case, since they can be photoionized and then deflected by the geomagnetic field. Furthermore, solar radiation pressure, although small, can distort the orbit.

For the hyperbolic particles $\varphi_{3}$, one can compute an escape flux (Jeans, 1925) for upward particles with velocities $\geq 11$ $\mathrm{km} \mathrm{s}^{-1}$. This escape flux is proportional to $(1 / 2) \varphi_{3}$. If there was an incoming flux of the same amount, there would be no net escape; this is not the case.

The external hyperbolic particles $\varphi_{4}$ are not of terrestrial origin. Even if some exist, there is no reason that they complete a Maxwellian velocity distribution.

Chamberlain (1963) established a theory to compute the various types of particles. Applications of this theory require use of numerical tables or recomputations of integrals. Chamberlain and Hunten (1987) reproduce these tables and made a correction in one of them.

Banks and Kockarts (1973b) showed that all types of particles can be obtained, either from Boltzmann's equation or from Liouville's theorem. Their results are analytical functions which can be summarized as follows.

If the error function $\Psi(x)$ is defined by

$\Psi(x)=(2 / \sqrt{\pi}) \int_{0}^{x} \exp \left(-t^{2}\right) \mathrm{d} x$,

five quantities $A, B, C, D, F$ can easily be computed:

$A=\Psi(E y)$

$B=\left(1-y^{2}\right)^{1 / 2}$ 
$C=\Psi[E y /(1+y)]$

$D=\exp \left[-E y^{2} /(1+y)\right]$

and

$F=1-C$

In these equations, $y=r_{c} / r$ is the ratio between the geocentric critical level $r_{c}$ and the geocentric distance $r$. The quantity $E$ is the ratio between the geocentric critical level and the scale height at this level for the considered constituent. The analytical expressions of the four types of particles can now be written

$\varphi_{1}=A-B \times C \times D$

$\varphi_{2}=B \times C \times D$

$\varphi_{3}=1-A-B \times D \times F$

and

$\varphi_{4}=B \times D \times F$.

Using Eqs. (35) to (38), it is straightforward to see that Eq. (28) is satisfied. These analytical results have seldom been used, except by Bertaux and Kockarts (1983) in their study of molecular hydrogen in the atmosphere of Titan.

As an example, Fig. 14 shows the four types of particles computed with Eqs. (35) to (38) for atomic hydrogen with an exospheric temperature of $1500 \mathrm{~K}$ and a critical level at $550 \mathrm{~km}$ altitude. As discussed above, all types of particles are not present, otherwise the vertical distribution would be hydrostatic.

Returning to our guide, i.e. Lyman- $\alpha$, it should be mentioned that observations of the scattered radiation are practically the only way to deduce atomic hydrogen abundance in the exosphere. This method requires, however, the solution of a radiative transfer problem.

Using measurements of the total equivalent width, Meier and Prinz (1970) deduced the atomic hydrogen concentration in the thermosphere. Bertaux (1978) measured the velocity distribution of hydrogen up to 7 Earth radii with the help of a Lyman- $\alpha$ absorption cell.

In their analysis, Vidal-Madjar and Thomas (1978) clearly showed that other escape mechanims must exist for atomic hydrogen. This important question has been discussed by Hunten (1990) from a historical viewpoint.

Lyman- $\alpha$ observations are still the most important tool for atomic hydrogen distributions (Bishop, 1999).

\section{Is there a future?}

The answer is definitely yes, provided two conditions are satisfied. First, younger scientists must have sufficient enthusiasm and skill to enter into the field of aeronomy. Second, reasonable funding must be made available.

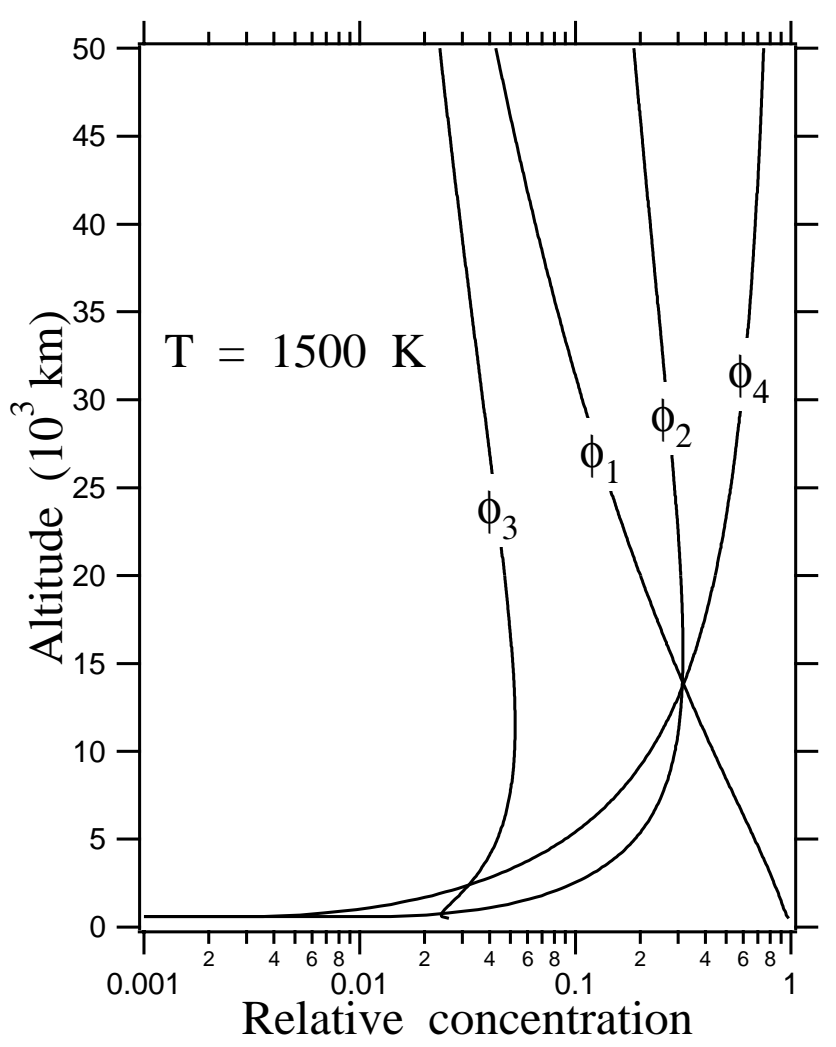

Fig. 14. Vertical distribution of the relative abundance of the four types of particles theoretically possible for atomic hydrogen with an exospheric temperature of $1500 \mathrm{~K}$.

The limited sketch that I have developed for this 20th Century emergent science can be extended to other planets of our solar system. Even for the terrestrial atmosphere, new measurements are still necessary to understand, in detail, all phenomena. For example, the polar mesospheric clouds, known for a long time, are still waiting for a complete explanation of their origin and structure. The increase of carbon dioxide can also have an effect on the middle atmosphere through radiative cooling (Akmaev and Fomichev, 2000). The corresponding decrease of lower thermospheric densities (Keating et al., 2000) has practical consequences on the lifetime of artificial satellites.

A better knowledge of solar irradiance is required over the whole spectral region, since this is a major driving mechanism for many atmospheric phenomena. As a consequence, the current effort to measure absorption and ionization cross sections, as well as reaction rates, should be continued. This would improve the accuracy of aeronomical modelling and measurements analysis. It is even possible that new processes will be discovered.

Although planetary atmospheres have been studied to some extent, many unknown phenomena will probably be discovered in the near future. This is an expanding field which will bring us many surprises.

One of the most exciting feature at the end of the 20th Century is the discovery of approximately 80 planets orbit- 
ing around nearby stars. These observations have essentially been made with ground-based telescopes. But the composition and structure of possible atmospheres are still subject to speculation, as a consequence of the lack of measurements.

Since life depends on the presence of oxygen, Akasofu (1999) suggested the development of a technique to measure the eventual auroral spectra or airglow, in order to detect spectroscopic characteristics of oxygen. If this challenge can be accomplished, it would be a great step towards the proof of the existence of extraterrestrial life.

These limited number of points in the present section clearly show that aeronomy can have a wonderful future.

Acknowledgements. I would like to thank the Editor in Chief D, Alcaydé for giving me the opportunity to write such a paper. Discussions with my young colleague $\mathrm{S}$. Chabrillat are greatly appreciated. The help of the two librarians of our institute, M. Jaumin and E. Rigo for their skill to find older papers is greatly appreciated. I thank also two referees for their constructive comments and remarks. My apologies to any international colleague who finds that here or his work is not cited. The subject is so vast that it is almost impossible to provide an exhaustive bibliography.

The Editor in Chief thanks J.-L. Bertraux and K. Tobiska for their help in evaluating this paper.

\section{References}

Akasofu, S.: Auroral spectra as a tool for detecting extraterrestrial life, EOS, 80, 397, 1999.

Akmaev, H. A. and Fomichev, V. I.: A model estimate of cooling in the mesosphere and lower thermosphere due to the $\mathrm{CO}_{2}$ increase over the last 3-4 decades, Geophys. Res. Letters, 27, 2113-2116, 2000.

Anderson, D. E., Meier, R. R., Hodges, R. R., and Tinsley, B. A.: Hydrogen Balmer alpha intensity distributions and line profiles from multiple scattering theory using realistic geocoronal models, J. Geophys. Res., 92, 7619-7642, 1987.

Banks, P. M.: Hydrogen ion velocity distributions in the ionosphere, Planet. Space Sci., 16, 759-773, 1968.

Banks, P. M. and Kockarts, G.: Aeronomy, Part A, 430, Academic Press, 1973a.

Banks, P. M. and Kockarts, G.: Aeronomy, Part B, 355, Academic Press, $1973 b$.

Bates, D. R. and Nicolet, M.: The photochemistry of atmospheric water vapor, J. Geophys. Res., 55, 301-327, 1950.

Baum, W. A., Johnson, F. S., Onerly, J. J., Rockwood, C. C., Strain, C. V., and Tousey, R.: Solar ultraviolet spectrum to 88 kilometers, Phys. Rev., 70, 781-782, 1946.

Berger, C., Biancale, R., Ill, M., and Barlier, F.: Improvement of the empirical thermospheric model DTM: DTM94 - a comparative review of various temporal variations and prospect in space geodesy application, J. Geodesy, 72, 161-178, 1998.

Bertaux J.-L.: Interpretation of OGO-5 line shape measurements of Lyman- $\alpha$ emission from terrestrial exospheric hydrogen, Planet. Space Sci., 26, 431-447, 1978.

Bertaux, J.-L. and Kockarts, G.: Distribution of molecular hydrogen in the atmosphere of Titan, J. Geophys. Res., 88, 8716-8720, 1983.

Bertaux, J.-L., Goutail, F., Dimarellis, E., Kockarts, G., and Van Ransbeeck, E.: First optical detection of atomic deuterium in the upper atmosphere from Spacelab 1, Nature, 309, 771-773, 1984a.

Bertaux, J.-L., Goutail, F., and Kockarts, G.: Observations of Lyman- $\alpha$ emissions of hydrogen and deuterium, Science, 225, 174-176, 1984b.

Bertaux, J.-L., Quémerais, E., Goutail, F., Kockarts, G., and Sandel, B.: Observations of atomic deuterium in the mesosphere from ATLAS 1 with ALAE instrument, J. Geophys. Res., 20, 507510, 1993.

Bishop, J.: Transport of resonant atomic hydrogen emissions in the thermosphere and geocorona: model description and applications, J. Quant. Spectrosc. Radiat. Trans., 61, 473-491, 1999.

Bishop, J.: Thermospheric atomic hydrogen densities and fluxes from dayside Lyman $\alpha$ measurements, J. Atmos. Solar-Terr. Phys., 63, 331-340, 2001.

Bishop, J., Harlander, J., Nossal, S., and Roesler, F. I.: Analysis of Balmer $\alpha$ intensity measurements near solar minimum, J. Atmos. Solar-Terr. Phys., 63, 341-353, 2001.

Brasseur, G. and Solomon, S.: Aeronomy of the middle atmosphere, $2^{\text {nd }}$ ed., 452, D. Reidel, 1986.

Breig, E. L. and Hanson, W. B.: Deuterium and hydrogen flows in the thermosphere, J. Geophys. Res., 96, 17 779-17 792, 1991.

Breig, E. L., Hanson, W. B., Hoffman, J. H., and Kayser, D. C.: In situ measurements of hydrogen concentration and flux between 160 and $300 \mathrm{~km}$ in the thermosphere, J. Geophys. Res., 81, 225238, 1976.

Breig E. L., Sanatani, S., and Hanson, W. B.: Deuterium in the daytime thermosphere, J. Geophys. Res., 92, 225-238, 1987.

Chabrillat, S.: Modélisation du changement global dans l'atmosphère moyenne, $\mathrm{PhD}$ thesis, Université Libre de Bruxelles, Available at ftp://ftp.oma.be/dist/simonc/thesis.pdf., 2001.

Chabrillat, S. and Kockarts, G.: Simple parameterization of the absorption of the solar Lyman-alpha line, Geophys. Res. Letters, 24, 2659-2662, 1997. Correction in Geophys. Res. Letters, 25, 79, 1998.

Chamberlain, J. W.: Planetary coronae and atmospheric evaporation, Planet. Space Sci., 11, 901-960, 1963.

Chamberlain, J. W. and Hunten, D. M.: Theory op planetary atmospheres, $2^{\text {nd }}$ ed., 481, Academic Press, 1987.

Chapman, S.: A theory of upper atmospheric ozone, Mem. Roy. Met. Soc., 3, 103-125, 1930.

Chapman, S. and Milne, E. A.: The composition, ionisation and viscosity of the atmosphere at great heights, Quart. J. Roy. Meteorol. Soc., 46, 357-398, 1920.

Chapman, S. and Cowling, T. G.: The mathematical theory of nonuniform gases, 431, Cambridge University Press, 1952.

DeMore, W. B., Sander, S. P., Hampson, R. F., Kurylo, M. J., Howard, C. J., Ravishankara, A. R., Kolb, C. E., and Molina, M. J.: Chemical kinetics and photochemical data for use in stratospheric modeling, JPL Publication 97-4, Pasadena, 1997.

Hann, J.: Die Zusamensetzung der Atmosphäre, Meteorol. Zeitschr., 20, 122-126, 1903.

Hall, L. A. and Hinteregger, H. E.: Solar extreme ultraviolet and its variation with solar rotation, J. Geophys. Res., 75, 6959-6965, 1970.

Hedin, A. E.: MSIS-86 thermospheric model, J. Geophys. Res., 92, 4649-4662, 1987.

Hedin, A. E.: Extension of the MSIS thermosphere model in the middle and lower atmosphere, J. Geophys. Res., 96, 1159-1172, 1991.

Herzberg, G.: "Uber die Spektren des Wasserstoffs, Ann. Physik, 84, 565-604, 1927. 
Herzberg, G.: Atomic spectra and atomic structure, Dover Publications, Inc., 1944.

Hines, C. O.: Doppler-spread parameterization of gravity-wave momentum deposition in the middle atmosphere. Part1: Basic formulation, J. Atmos. Solar-Terr. Phys., 59, 371-386, 1997.

Hines, C. O.: Correction to 'Doppler-spread parameterization of gravity-wave momentum deposition in the middle atmosphere. Part1: Basic formulation', J. Atmos. Solar-Terr. Phys., 61, 941, 1999.

Hinteregger, H. E.: Interplanetary ionization by solar extreme ultraviolet radiation, Astrophys. J., 132, 801-811, 1960.

Hinteregger, H. E. and Hall, L. A.: Solar extreme ultraviolet emissions in the range 260-1300 $\AA$ observed from OSO-III, Solar Phys., 6, 175-182, 1969.

Hirschfelder, J. O., Curtiss, C. F., and Bird, R. B.: Molecular theory of gases and liquids, 1219, John Wiley and Sons, 1954.

Holton, J. R.: An introduction to dynamic meteorology, 319, Academic Press, 1972

Holton, J. R.: The dynamic meteorology of the stratosphere and mesosphere, 218, Meteorological Monographs, 15, 37, American Meteorological Society, Boston, 1975.

Houghton, J. T.: The physics of atmospheres, 203, Cambridge University Press, 1977.

Humphreys, W. J.: Distribution of gases in the atmosphere, Bull. Mount Weather Obs., 2, 66-69, 1910.

Hunten, D. M.: Vertical transport in atmospheres, in: Atmospheres of Earth and the Planets, (Ed) McCormac, B. M., 59-71, D. Reidel, 1975.

Hunten, D. M.: Kuiper prize lecture: escape of atmospheres, ancient and modern, Icarus, 85, 1-20, 1990.

Hunten, D. M. and McElroy, M. B.: Metastable $\mathrm{O}_{2}\left({ }^{1} \Delta\right)$ as a major source of ions in the D region, J. Geophys. Res., 73, 2421-2428, 1968.

Hunten, D. M. and Strobel, D. F.: Production and escape of terrestrial hydrogen, J. Atmos. Sci., 31, 305-317, 1974.

Jeans, J. H.: The dynamical theory of gases, Cambridge University Press, 1925, republished by Dover Publications, Inc., 1954.

Keating, G. M., Tolson, R. H. and Bradford, M. S.: Evidence of long term global decline in the Earth's thermospheric densities apparently related to anthropogenic effects, Geophys. Res. Letters, 27, 1523-1526, 2000.

Kockarts, G.: Distribution of hydrogen and helium in the upper atmosphere, J. Atmos. Terr. Phys., 34, 1729-1743, 1972a.

Kockarts, G.: Deuterium distribution in the Earth's upper atmosphere, Space Res., 12, 1047-1050, 1972b.

Kockarts, G.: Penetration of solar radiation in the Schumann-Runge bands of molecular oxygen: a robust approximation, Ann. Geophysicae, 12, 1207-1217, 1994.

Kockarts, G.: Aéronomie: Physique et chimie de l'atmosphère, 207, DeBoeck Université, Bruxelles, 2000.

Kockarts, G. and Nicolet, M.: Le problème aéronomique de l'hélium et de l'hydrogène neutres, Annales de Géophysique, 18, 269-290, 1962.

Kockarts, G. and Nicolet, M.: L'hélium et l'hydrogène atomique au cours d'un minimum d'activité solaire, Ann. de Géophysique, 19, 370-385, 1963.

Krasnopolsky, V. A.: Spectroscopic detection of terrestrial deuterium, Geophys. Res. Letters, 25, 2115-2118, 1998. Correction in Geophys. Res. Letts., 25, 3741-3743, 1998.

Lacoursière, J., Meyer, S. A., Faris, G. W., Slanger, T. G., Lewis, B. B., and Gibson, S. T.: The $\mathrm{O}\left({ }^{1} \mathrm{D}\right)$ yield from $\mathrm{O}_{2}$ photodissociation near H Lyman- $\alpha$ (121.6 nm), J. Chem. Phys., 110, 1949-
1959, 1999.

Lemaire, P., Charra, J., Jouchoux, A., Vidal-Madjar, A., Artzner, G. E., Vial, J., Bonnet, R. M., and Skumanich, A.: Calibrated full-disk H I Lyman- $\alpha$ and Lyman- $\beta$ profiles, Astrophys. J., 223, L55-L58, 1978.

Lewis, B. R. and Carver, J. H.: Temperature dependence of carbon dioxide photoabsorption cross section between 1200 and $1970 \AA$, J. Quant. Spectros. Radiat. Transfer, 30, 297-309, 1983.

Lewis, B. R., Varvadas, I. M. and Carver, J. H.: The aeronomic dissociation of water vapor by solar Lyman- $\alpha$ radiation, J. Geophys. Res., 88, 4935-4940, 1983.

Lilensten, J. and Blelly, P.-L.: Du Soleil à la Terre, aéronomie et météorologie de l'espace, 419, Presses Universitaires de Grenoble, 1999.

Lindzen, R. S.: Turbulence and stress owing to gravity wave and tidal breakdown, J. Geophys. Res., 86, 9707-9714, 1981.

Liu, S. C. and Donahue, T. M.: The aeronomy of hydrogen in the atmosphere of the Earth, J. Atmos. Sci., 31, 1118-1136, 1974.

London, J., Rottman, G. J., Woods, T. N., and Wu, F.: Time variation of solar UV irradiance as measured by the SOLSTICE (UARS) instrument, Geophys. Res. Letts., 20, 1315-1318, 1993.

Lyman, T.: An extension of the spectrum in the extreme ultraviolet, Nature, 93, 241, 1914.

Mason, E. A. and Marrero, T. R.: The diffusion of atoms and molecules, in: Advances in Atomic and Molecular Physics, (Eds) Bates, D. R., and Esterman, I., 6, 155-232, Academic Press, 1970.

Meier, R. R.: Ultraviolet spectroscopy and remote sensing of the upper atmosphere, Space Sci. Revs, 58, 1-185, 1991.

Meier, R. R.: Solar Lyman series profiles and atomic hydrogen excitation rates, Astrophys. J., 452, 462-471, 1995.

Meier, R. R. and Prinz, D. K.: Absorption of the solar Lyman-alpha line by geocoronal atomic hydrogen, J. Geophys. Res., 75, 69696979, 1970.

Minschwaner, K. and Siskind, D. E.:, A new calculation of nitric oxide photolysis in the stratosphere, mesosphere, and lower thermosphere, J. Geophys. Res., 98, 20 401-20 412, 1993.

Nicolet, M., and Aikin, A. C.: The formation of the D region of the ionosphere, J. Geophys Res., 65, 1469-1483, 1960.

Peixoto, J. P. and Oort, A. H.:, Physics of climate, 520, American Institute of Physics, New York, 1992.

Rees, M. H.:, Physics and chemistry of the upper atmosphere, 289, Cambridge University Press, 1989.

Rense, W. A.: Intensity of Lyman-alpha line in the solar spectrum, Phys. Rev., 91, 299-302, 1953.

Richards, P. G., Fenelly, J. A., and Torr, D. G.: EUVAC: A solar EUV flux model for aeronomic calculations, J. Geophys. Res., 99, 8981-8992, 1994.

Rottman, G. J.: Solar ultraviolet irradiance and its temporal variation, J. Atmos. Solar-Terr. Phys., 61, 37-44, 1999.

Schunk, R. W. and Nagy, A. E.: Ionospheres: Physics, plasma physics and chemistry, 554, Cambridge University Press, 2000.

Slanger, T. G. and Black, G.: Photodissociative channels at $1216 \AA$ for $\mathrm{H}_{2} \mathrm{O}, \mathrm{NH}_{3}$, and $\mathrm{CH}_{4}$, J. Chem. Phys., 77, 2432-2437, 1982.

Thuillier, G., and Bruinsma, S.: The Mg II index for upper atmosphere modelling, Ann. Geophysicae, 19, 219-228, 2001.

Tinsley B. A.: Hydrogen in the upper atmosphere, Fund. Cosmic Phys., 1, 201-300, 1974

Tobiska, K. W., Woods, T., Eparvier, F., Viereck, R., Floyd, L., Bouwer, D., Roottman, G. J., and White, O. R.: The SOLAR2000 empirical solar irradiance model and forecast tool, J. Atmos. Solar Terr. Phys., 62, 1233-1250, 2000. 
Tohmatsu, T.: Compendium of aeronomy, 509, Terra Scientific Pub. Cy., Tokyo, 1990.

Tousey, R., Purcell, J. D., Austin, W. E., Garrett, D. L., and Widing, K. G.: New photographic spectra of the Sun in the extreme ultraviolet, Space Res., 4, 703-718, 1964.

Tousey, R., Austin, W. E., Purcell, J. D., and Widing, K. G.: The extreme ultraviolet emission from the Sun between the Lymanalpha lines of H I and C VI, Ann. d'Astrophys., 28, 755-773, 1965.

Vidal-Madjar, A. and Thomas, G. E.: The terrestrial hydrogen problem, Planet. Space Sci., 26, 863-871, 1978.

Viereck, R. A. and Puga, L. C.: The NOAA Mg II core-to-wing solar index: Construction of a 20-year time series of chromo- spheric variability from multiple satellites, J. Geophys. Res., 104, 9995-10005, 1999.

Wegener, A.: Untersuchungen über die Natur der obersten Atmosphärenschichten, Physik. Zeitschr., 12, 170-178, 1911.

Whitten, R. C. and Poppoff, I. G.: Fundamentals of aeronomy, 446, John Wiley, 1971.

Wiese W. L., Smith M. W., and Glennon B. M.: Atomic transition probabilities, Vol. 1, National Bureau of Standards, U.S. Government Printing Office, 1996.

Yung, Y. L., Wen, J.-S., Moses, J. I., Landry, B. M., Allen, M., and Hsu, K.-J.: Hydrogen and deuterium loss from the terrestrial atmosphere: a quantitative assessment of nonthermal escape fluxes, J. Geophys. Res., 94, 14 971-14 989, 1989. 